\title{
Design of the A.C. Dipole and Compensation of Saturation Effects for the LANL Synchrotron
}

\author{
J. Liu*
}

S. Greene

\begin{abstract}
DISCLAIMER
This report was prepared as an account of work sponsored by an agency of the United States Government. Neither the United States Governnient nor any agency thereof, nor any of their employees, makes any warranty, express or implied, or assumes any legal liability or responsibility for the accuracy, completeness, or usefulness of any information, apparatus, product, or process disclosed, or represents that its use would not infringe privately owned rights. Reference herein to any specific commercial product, process, or service by trade name, trademark. manufacturer, or otherwise does not necessarily constitute or imply its endorsement, recommendation, or favoring by the United States Government or any agency thereof. The views and opinions of authors expressed herein do not necessarily state or reflect those of the United Siates Government or any agency thereof.
\end{abstract}

\section{MASTER}

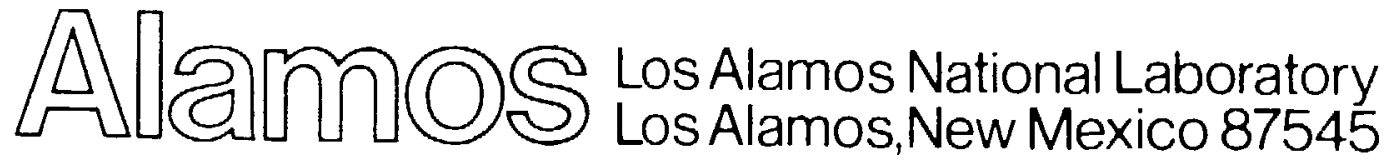


DESIGN OF THE A.C. DIPOLE AND COMPENSATION OF

SATURATION EFFECTS FOR THE LANL SYNCHROTRON

by

J. LIu and S. Greene

\section{ABSTRACT}

An A.C. dipole magnet, which can work in two accelerator energy modes of $45 \mathrm{GeV}$ and $60 \mathrm{GeV}$, is reported for the LANL synchrotron. In order to reach high uniformity of magnetic field distribution in good fieid region, some effective measures are presented to compensate field errors due to the saturation at both edges of magnet poles.

\section{Introduction}

The LANL $45 \mathrm{GeV}$ synchrotron utilizes separated function magnets and a total of 80 dipoles and 74 quadrupoles are distributed in the main ring[1]. Preliminary magnet designs have been investigated based on the POISSON computer program[2],[3]. A comparison between dipole designs is also made so as to choose a better dipole configuration which is cost effective and least expensive in construction, and has less complexity of manufacture[4]. In these dipole designs, three important factors are considered: 1).machine upgrading plan to $60 \mathrm{GeV}$ energy, 2). high field uniformity requirement, and 3). possibilities of coil damage caused by particle spills and radiation. Because of the last reason, we cannot utilize some magnet models like a window frame type, types with compensation coils in the midplane of the pole gap. So we choose a conventiona: H-type magnet configuration and put exciting coils far from the midplane to avoid possible coil damage.

This dipole magnet has a field strength of $0.225 \mathrm{~T}$ at the injection energy of $6 \mathrm{GeV}$ and of $1.5 \mathrm{~T}$ at the final energy of $45 \mathrm{GeV}$, and $2 \mathrm{~T}$ at the extended energy of $60 \mathrm{GeV}$. The field range is so large that when the magnet is adjusted from low field to high field, the magnetic field error is increased to an unacceptable extent due to the appearance of iron saturation at both edges of poles. The multipole error requirements of the LANL magnet are given in table 1 .

Table 1. Multipole error requirements of the LANL dipole

\begin{tabular}{|c|c|c|c|c|}
\hline \multirow[t]{2}{*}{ Type } & \multicolumn{2}{|c|}{ Systematic Error } & Random & \multirow{2}{*}{$\begin{array}{l}\text { Error } \\
\text { Orientation }\end{array}$} \\
\hline & Strength & 0rientation & Strength & \\
\hline dipole & 0.0 & & 1. $0 \mathrm{E}-4$ & random \\
\hline quadrupole & 0.0 & & $0.3 \mathrm{E}-4$ & random \\
\hline sextupole & $\begin{array}{l}-1.5 E-4 \\
\text { (injection) }\end{array}$ & upright & $0.5 \mathrm{E}-4$ & upright \\
\hline & $\begin{array}{l}+3.0 \mathrm{E}-4 \\
\text { (extraction) }\end{array}$ & uprighe & O. $5 \mathrm{E}-4$ & upright \\
\hline $\begin{array}{l}\text { octupole } \\
\text { decapole }\end{array}$ & $\begin{array}{r}0.7 E-4 \\
-0.5 E-4\end{array}$ & $\begin{array}{l}1 / 2 \text { skew } \\
\text { upright }\end{array}$ & $\begin{array}{l}0.3 E-4 \\
0.3 E-4\end{array}$ & $\begin{array}{l}\text { random } \\
\text { random }\end{array}$ \\
\hline
\end{tabular}


For a conventional type magnet, the requirements in table 1 seem to be high and it is hard to reach them without any adjustment mearis. Now a new dipole design is developed based on previous experience. This magnet can work in two accelerator energy modes, $45 \mathrm{GeV}$ and $60 \mathrm{GeV}$. Utilizing this configuration with a combined compensation measure, it is possible to meet field accuracy requirements and it is considered realistic and reliable.

\section{Dipole Under $45 \mathrm{GeV}$ Energy Range}

For the synchrotron with different energy purposes in primary and upgrading projects, we are going to make the dipole in two steps. In our design, the first step is for $45 \mathrm{GeV}$ energy range. Because a lower magnetic field condition is needed in this energy range, we can adopt the general way of adding shims to obtain higher field accuracy. The dipole magnet configuration is shown in Fig. 1 . It has a good field aperture of $16 \mathrm{~cm}$ wide by $8.6 \mathrm{~cm}$ high and an overall dimension $1.26 \mathrm{~m}$ by $0.8 \mathrm{~m}$ by $8 \mathrm{~m}$. The magnet size is moderate in comparison with other similar kind dipole magnets[5],[6]. Exciting coils are put behind the pole tips and separated from the field gap, which avoids possible coil damage caused by particle spills and synchrotron radiation. In the case of flat pole surfaces, when the field changes from $0.225 \mathrm{~T}$ to $1.503 \mathrm{~T}$, a field error of $0.15 \%$ will appear within good field region because of small iron saturation effect. So as to remedy the field error, very small shims are shaped at both pole edges with computer aided design. In Fig. 2, some curves of magnetic field distribution are given. The Fourier analyses of magnetic field harmonics are made from which we can know multipole errors are close to design requirements. The data of field and coil, and analysis results of multipole errors are given in table 2 and table 3 respectively.

Table 2. Field and exciting coil data

Field Daté

field range $(\mathrm{T})$

uni formity

good field region ( $W \times \mathrm{H} \mathrm{cm}$ )

Exciting Coil Data

coil dimension $(\mathrm{cm})$

conductor size $(\mathrm{cm})$

wires/cond. (wire dia.)

turns

$0.225-2.0$
$<0.03 \%$
$16 \times 8$
$18 \times 12$
$2 \times 2$
$200(1 \mathrm{~mm})$
18

Table 3. Multipole error analysis in lower field range

\begin{tabular}{ccccccr} 
Average Field & \multicolumn{7}{c}{ Multipole Error } & Strength & (Gauss) \\
Strength (Gauss) & Dipole & Quadrupole & Sextupole & Octupole & Decapole & $12-$ pole \\
2294.487 & -0.112 & -0.166 & 0.079 & -0.034 & 0.016 & -0.009 \\
7114.563 & -0.326 & -0.493 & 0.237 & -0.101 & 0.045 & -0.025 \\
10156.045 & -1.128 & -1.363 & 0.291 & -0.090 & 0.038 & -0.016 \\
12024.956 & -1.218 & -1.473 & 0.308 & -0.089 & 0.033 & 0.010 \\
15067.916 & 0.278 & 0.339 & -0.248 & 0.204 & -0.154 & 0.130
\end{tabular}

In exciting coil design, we apply smaller exciting coil frames so as 
to reduce magnet dimension and material costs bscause if we utilize bigger coil size, the magnet expense problem will become significant, compared with operation costs. In coil cooling, it is easy to solve coil heat caused by an increase of electrical power when we use more water-circuits. In fact, there is not obvious difference in cooling between A.C. and D.C. magnets in the case of negligible eddy current effects.

\section{Dipole Under $60 \mathrm{GeV}$ Energy Range}

After finishing the first procedure, we can consider the next step of high field design. The accelerator will utilize the same magnet components to fit extended energy of $60 \mathrm{GeV}$. This upgrading plan is possible but it increases the complexity of magnet design. When the magnetic field strength changes from $0.225 \mathrm{~T}$ to $2.0 \mathrm{~T}$, iron permeability changes nonlinearly and quickly at the edges near exciting coils, which causes the field to drop and produce a larger gradient along a horizontally traverse axis. So as to meet the extended energy purpose, we have to utilize compensation coils to adjust the field error due to the serious saturation effe:t in iron at high field.

A couple of compensation coils are put on pole sufaces as shown in Fig. 3. Though compensation coils cannot change the iron saturation property, it can adjust field uniformity because it can produce an additional field to be added to the guide field. When the additional field is positive, the ends of the field distribution will rise but it needs more compensation current. And when the additional field is negative, it will somewhat reduce center guide field strength. The former is not suitable to this case because large current density will cause compensation coil heat and increase the complexity in coil cooling. We would rather choose the latter since it needs less current and it is not necessary to cool coils. Good uniformity of $<0.02 \%$ can be obtained as shown in Fig. 4. The field and compensation coil parameters are listed in table 4 and multipole error analyses are given in table 5 .

Table 4. The field and coil parameters of the dipole

Field Data

$\begin{array}{ll}\text { field range }(T) & 0.225-2.0 \\ \text { uniformity } & <0.02 \% \\ \text { good field region }(\mathrm{W} \times \mathrm{H} \mathrm{cm}) & 16 \times 8\end{array}$

Compensation Coil Data

coil dimension $(\mathrm{cm}) \quad 7 \times 0.3$

conductor size (cm) $0.3 \times 0.3$

turns 23

Table 5. Multipole error analysis in high field range

\begin{tabular}{ccccccc} 
Average Field & \multicolumn{5}{c}{ Multipoie Error } & Strength (Gauss) \\
Strength (Gauss) & Dipole & Quadrupole & Sextupole & Octupole & Decapole & $12-$ pole \\
16058.728 & 0.683 & 0.486 & 0.104 & 0.085 & -0.093 & 0.087 \\
16889.662 & 0.164 & -0.260 & 0.362 & 0.054 & -0.083 & 0.085 \\
18503.982 & 0.752 & 0.183 & 0.301 & 0.297 & -0.251 & 0.211 \\
20005.695 & -0.295 & -1.674 & 0.843 & 0.622 & -0.503 & 0.413
\end{tabular}


The compensation coil is relatively immune to damage by radiativin and spilled beam because usually spills happen on the horizontal plane along the tangent direction of particle orbit and the radiative opening angle is very small, approximately equaling to the wavelength of synchrotron radiation. Based on considerations of further simplifying operation procedure of compensation coils, we are going to use solid conductors to reduce coil resistance, and parallel coil turns to lover voltage between conductor ends. From simple estimates, no damage to the coils will be caused because of the negligible resistance heating and eddy current losses. And since the magnet core is made of stacked steel laminates, not much heat can be produced. By estimate, pole surfaces do not get unacceptably hot even under the worst circumstances. Compensaticn coil heat can be dissipated through the magnet body.

In this case, an additional small power supply is needed, and there is a synchronous relation between exciting power source and compensation power source as in Fig. 5 .

IV. Conclusion

Because it is straightforward to manufacture, a two-step construction procedure of the dipole is commended for the proposed synchrotron. In the future, when the energy upgrading plan of the accelerator is realized, the magnet can be improved conveniently. Some useful engineering data are given in the appendix t: tached below.

References:

[1]. THE PHYSICS AND A PLAN FOR A 45 GEV FACILITY THAT EXTENDS THE HIGH INTENSITY CAPABILITY IN NUCLEAR AND PARTICLE PHYSICS. Los Alamos National Laboratory report LA-10720-MS (May 1986).

[2]. PRELIMINARY INVESTIGATION AND DESIGN OF AN A. C. DIPOLE MAGNET FOR AN ADVANCED HADRON FACILITY SYNCHROTRON, International Hadron Facility Conference, Santa Fe, New Mexico, USA, February 2-5, 1987, Los Alamos National Laboratory document LA-UR-87-1444.

[3]. J. Liu, S. Greene, and T. Hunter, PRELIMINARY DESIGN OF A. C. QUADRUPOLE MAGNETS FOR AN ADVANCED HADRON FACILITY SYNCHROTRON, to be published in the proceedings of the International Hadron Facility Conference, Santa Fe, New Mexico, USA, February 2-5, 1987.

[4]. A COMPARISON BETWEEN SEVERAL DESIGNS OF H TYPE DIPOLE FOR AN ADVACED HADRON FACILITY, Los Alamos National Laboratory report LA-11028-MS.

[5]. CHARACTERISTICS OF LATTICE AND MAGNET SYSTEM OF TARN II, A. Noda et al. IEEE Transactions on Nuclear Science, Vol. NS-32, No. 5, 0ctober, 1985.

[6]. EHF MAIN RING DIPOLE MAGNET DESIGN DATA, European Hadron Facility report EHF/SIN/MG-05, for the Swiss Institute for Nuclear Research, Villigen, Switzerland (September 1986) 
[Appendix] Basic parameters of the dipole magnet for the LANL synchrotron

Synchrotron Energy

Magnet Data

Magnet dimension (m)

Pole width $(\mathrm{cm})$

Lamination thickness $(\mathrm{cm})$

Lamination stacking factor

Steel weight (Ton)

Copper weight (Ton)
$45 \mathrm{GeV}$

$60 \mathrm{GeV}$

Field Data

Field range ( $\mathrm{T}$ )

Good field region ( $W \times \mathrm{H} \mathrm{cm}$ )

Uni formity

Main Coil Data

Coil dimension $(\mathrm{cm})$

Mean length (m)

Turns/coil

Conductors/turn

Conductor size $(\mathrm{cm})$

Wires/cond. (wire dia.)

Copper space factor

Coil resistance $(\mathrm{mOhm})$ *

Compensation Coil Data

Coil dimension $(\mathrm{cm})$

Mean length (m)

Turns/coil

Conductor size $(\mathrm{cm})$

Coil resistance $(\mathrm{mOhm})$ *

Operation Data (/mag)

Magnet:

Peak stored energy ( $\mathrm{KJ}$ )

Inductance $(\mathrm{mH})$

Main coil:

$\operatorname{Imax}(A)$

$\operatorname{Imin}(A)$

Idc (A)

$\operatorname{Iac}(A)$

Peak current density $(A / C m \star \star 2)$

Peak coil voltage (V)

Induced voltage (KV)

Compensation coil:

Peak current (A)

Peak current density $(\mathrm{A} / \mathrm{Cm} \star \star 2)$

Peak coil voltage (V)

Induced voltage (V)

Power Data (/mag)

Iron core loss (KW)

Main coil A.C. power (KW)

Main coil D.C. power (KW)
$1.26 \times 0.8 \times 8$

40

0.1

$98 \%$

53

6.8

$0.225-1.5$

$16 \times 8.4$

$<0.03 \%$

$18 \times 12$

17.56

18 (in series)

3 (in parallel)

$2 \times 2$

$200(1 \mathrm{~mm})$

$50 \%$

17.07

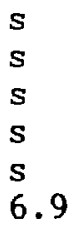

$0.225-2.0$

$16 \times 8$

$<0.02 \%$
298

68.67

2944.44

440

1692.22

1252.22

490.74

101

$-2.40$
$7 \times 0.3$

16.48

23 (in parallel)

$0.3 \times 0.3$

1.43

674

50.50

5166.67

440

2803.34

2363.34

861.11

176

$-2.46$

670

$-323.67$

0.96

$-80.22$

2.61

47.67

268.30
1.84

13.38

97.76 
Edidy loss in main coil (KW)

Compensation mean power (W)

1.61

Eddy loss in comp. coil (W)

Total (KW)

\section{Cooling Data}

Temperature rise (F degree) 5

Pressure drop (1b/in $\star \star 2) \quad 15.8241$

Water flow/cirsuit (gal/min) 7.5544

Water velocity ( $\mathrm{ft} / \mathrm{sec}$ ) 13.0293

Water circuits

18
3.13

321

358

322.39

\section{5}

117.9951

20.6287

35.5790

18

* Copper resistivity $\mathrm{p}=1.8 \mathrm{E}-60 \mathrm{hm} \star \mathrm{cm}$ 


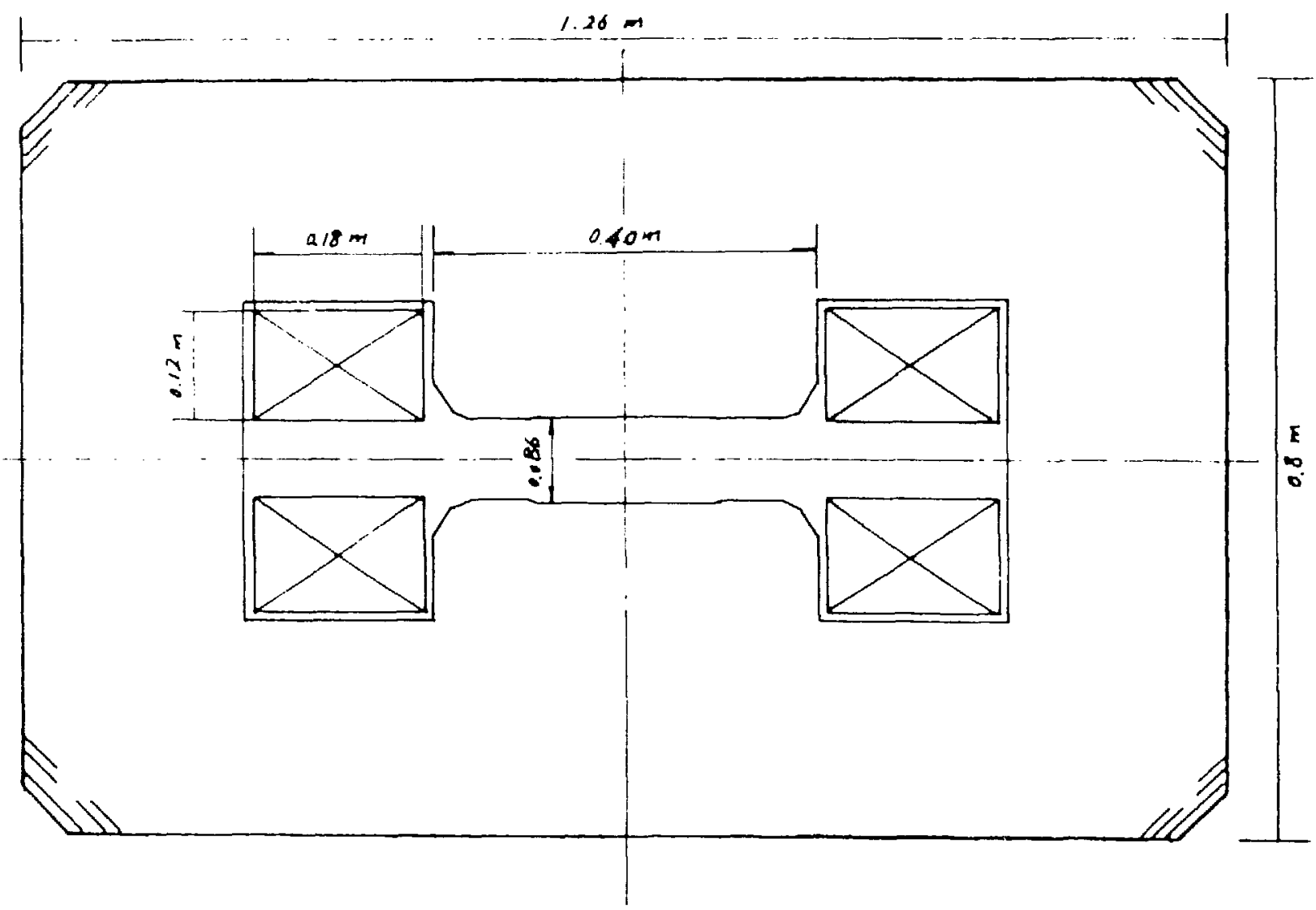

Fig. 1 A dipole magnet configuration

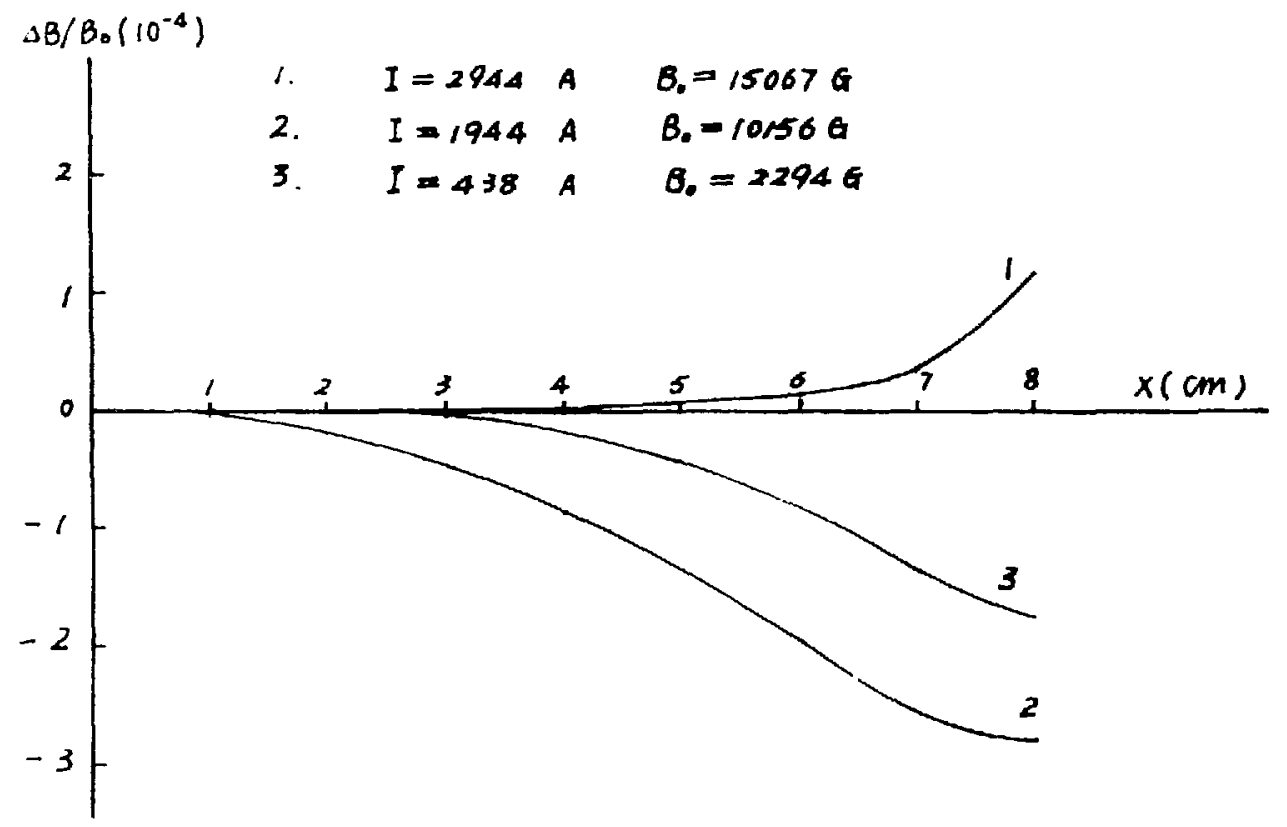

Fig. 2 Magnetic field distribution 


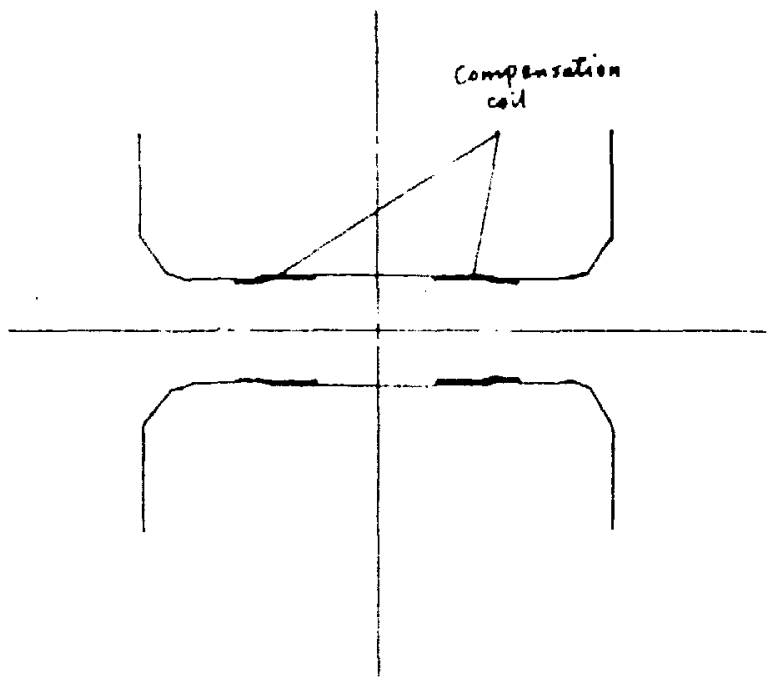

Fig. 3 Magnet compensation

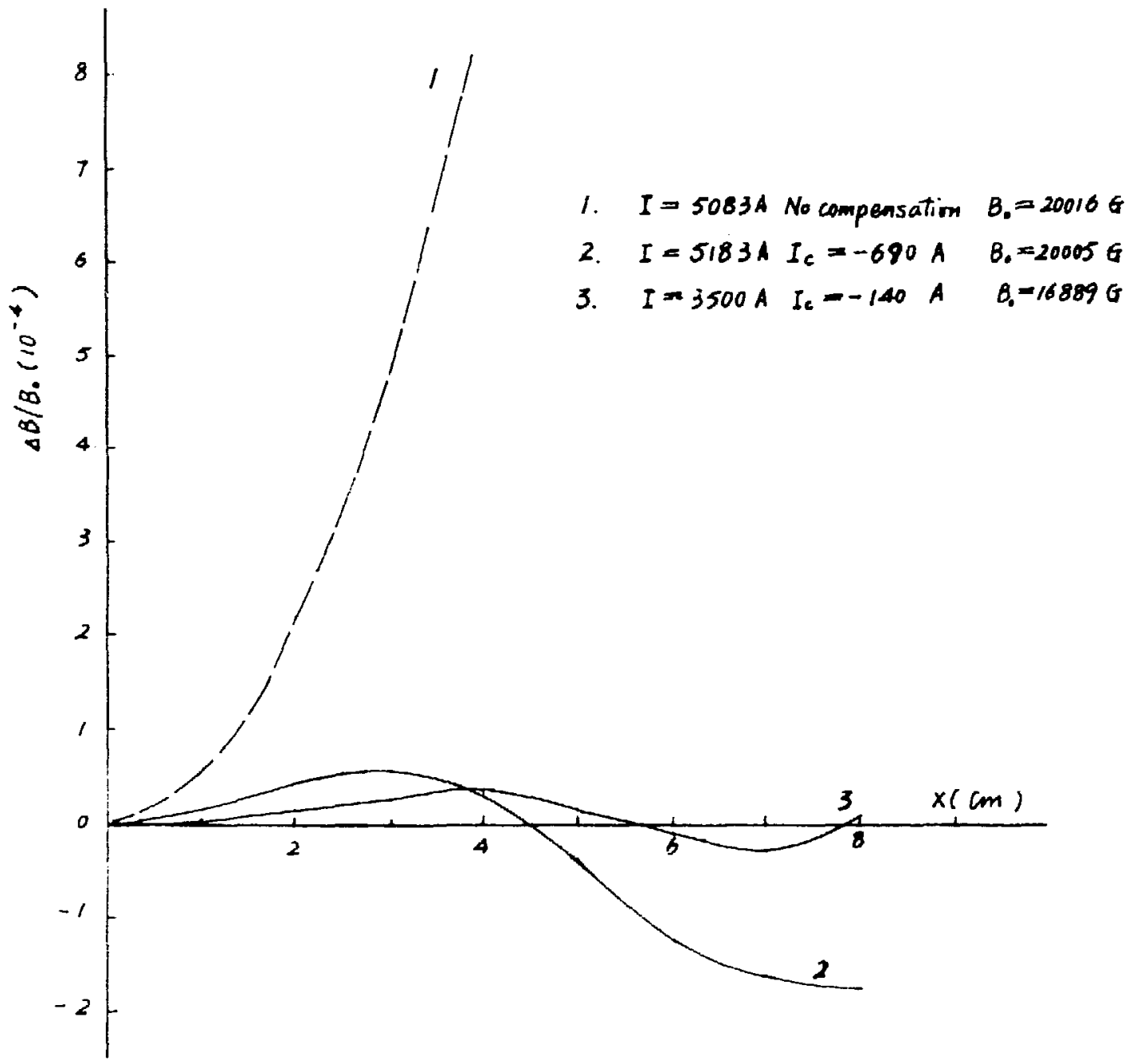

Fig. 4 Magnetic field distribution 


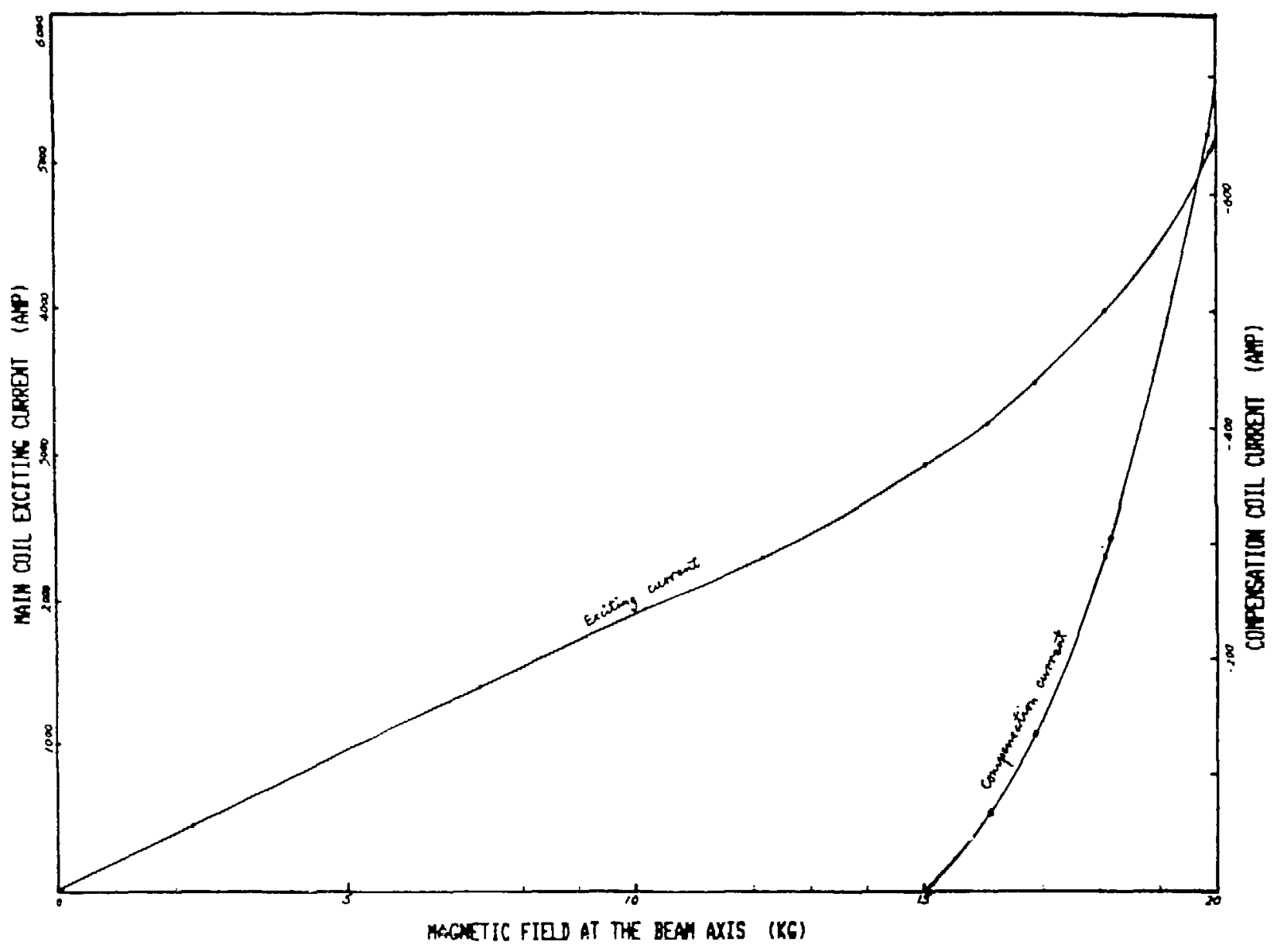

Fig. 5 Relation betueen exciting current and conpensation current 